\title{
Graphophonological processes in dyslexic readers of French: A longitudinal study of the explicitness effect of tasks
}

\author{
Daniel Daigle • Rachel Berthiaume • Anne Plisson • \\ Elisabeth Demont
}

Received: 11 July 2011 / Accepted: 5 March 2012

(C) The International Dyslexia Association 2012

\begin{abstract}
Given the well-acknowledged phonological deficit found in dyslexic children, this study was aimed at investigating graphophonological processes in dyslexic readers of French over a 1-year period. Among the different types of phonological processing can be distinguished those related to phonological awareness based on knowledge of the oral language and graphophonological processes based on correspondences between the oral and the written language. In this study, we evaluated graphophonemic and graphosyllabic processes using, in each case, two different tasks varying in the degree of cognitive constraint associated with the task (CC- vs $\mathrm{CC}+$ ). Twenty 11 year-old dyslexic students were compared with younger normal-readers of the same reading level (RA, $n=26)$ and to normal-readers of the same age $(\mathrm{CA}, n=24)$. Two variables were considered in the analyses: accuracy and response latency. Results show that dyslexic readers do process written items at the graphophonological level. Also, results indicate main effects of task $(\mathrm{CC}-\mathrm{vs} \mathrm{CC}+)$, time (T1 vs T2), and group (DYS vs RA vs CA). In general, dyslexic participants' performances are comparable to those of RA and differ from those of CA.
\end{abstract}

Keywords Dyslexia $\cdot$ Grapheme $\cdot$ Longitudinal study $\cdot$ Reading $\cdot$ Syllable $\cdot$ Task effect

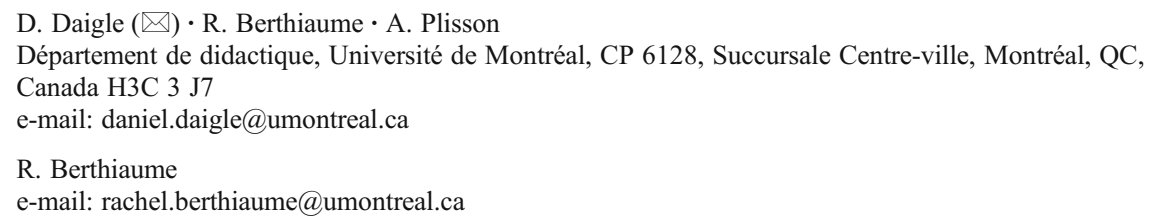

\section{A. Plisson}

e-mail: anne.plisson@umontreal.ca

E. Demont

Faculté de psychologie, Université de Strasbourg, 12 rue Goethe, Strasbourg, France 67000

e-mail: elisabeth.demont@unistra.fr 


\section{Introduction}

Learning to read is a formidable task for most children and is especially so for those who are dyslexic (Snowling, 2000). In alphabetic languages, reading acquisition necessitates the development of analytic abilities allowing the learner first to become conscious of the segmental nature of the oral language and second, to connect written material to oral language (Gombert, 1992, 2003). This connection would rely specifically on graphemephoneme correspondences (Adam, 1990; Coltheart, Curtis, Atkins, \& Haller, 1993; Coltheart, Rastle, Perry, Langdon, \& Ziegler, 2001). Automatization of this process would ease the activation of representations of words in the mental lexicon, making more cognitive energy available for comprehension processes (Kirby, Desrochers, Roth, \& Lai, 2008; Stanovich, 1990). Studies investigating beginning reading acquisition have reached two main interrelated conclusions: Word recognition is founded on phonological awareness abilities, and specific orthographic segments constitute reading units. In both cases, phonological processing is involved.

First, a very large body of theoretical and empirical studies has shown that phonological awareness is related to reading (e.g., Anthony \& Lonigan, 2004; Caravolas \& Landerl, 2010; Goswami \& Bryant, 1990; Jongejan, Verhoeven, \& Siegel, 2007; Plaza \& Cohen, 2003; Vellutino, Fletcher, Snowling, \& Scanlon, 2004; Wagner, Torgesen, \& Rashotte, 1994; Whitehurst \& Lonigan, 1998; Ziegler \& Goswami, 2005). Phonological awareness, defined as the ability to perceive and manipulate word units at the oral level, is considered the motor of word recognition development (Demont \& Gombert, 2007; Siegel, 2003; Snowling, 2000; Ziegler \& Goswami, 2005).

Second, several studies have shown that graphemes and written syllables are reading units and that graphophonemic processes (i.e., the correspondences between graphemes and phones) are distinct from graphosyllabic processes (i.e., the correspondences between written and oral syllables) in normal readers (Colé, Magnan, \& Grainger, 1999; Doignon \& Zagar, 2006; Duncan \& Seymour, 2003; Ferrand, Segui, \& Grainger, 1996; MaïonchiPino, Magnan, \& Ecalle, 2010b; Prinzmetal, Hoffman, \& Vest, 1991; Prinzmetal, Treiman, \& Rho, 1986; Rastle \& Coltheart, 1998; Rey, Jacobs, Schmidt-Weigand, \& Ziegler, 1998; Rey, Ziegler, \& Jacobs, 2000; Sprenger-Charolles \& Siegel, 1997).

Considering that phonological awareness studies are based on oral tasks and that studies investigating graphophonological processes are founded on written tasks, one could ask why refer to the former when aiming at the latter. First of all, when studying phonological processing, it is important to distinguish phonological awareness processes from those involved in graphophonological processing (Hagiliassis, Pratt, \& Johnston, 2006; Kirby et al., 2008). It is not because one can process phonological units at the oral level that one can also process the corresponding written units. Second, phonological awareness studies offer a methodological framework for investigating graphophonological processing. Indeed, one major interest of phonological awareness tasks is that they contrast in terms of cognitive constraints, making actions required of subjects to vary on a continuum ranging from less explicit to more explicit (Bialystok, 2001; Gombert, 1992; Lecocq, 1991; Lefrançois \& Armand, 2003; Yopp, 1988). For example, an identification task does not require the same level of awareness as that involved in a permutation task, which is more complex. According to Bialystok (2001), the task will be more explicit if it requires a higher level of linguistic knowledge and/or involves a higher level of cognitive constraints. The opposite is considered true for less explicit tasks. In this paper, we adopted Bialystok's point of view and varied the tasks in accordance with the cognitive constraints necessitated by each. Third, studies investigating graphophonological processes have tried to identify what orthographic 
units constitute reading units, assuming that these reading units would be the ones assembled in word recognition, but have not used tasks varying in terms of constraints. Considering constraints attached to graphophonological tasks may shed some light on processes involved in reading and may contribute to explaining reading difficulties in exceptional children such as dyslexic readers.

\section{The case of dyslexic readers}

As in normal readers, a substantial body of empirical and theoretical research has focused on investigating phonological awareness in dyslexic readers (e.g., Bosse \& Valdois, 2003; Casalis, 2003; de Jong \& van der Leij, 2003; Demont, 2003; Goswami, 2002; Larkin \& Snowling, 2007; Manis, Custodio, \& Szeszulski, 1993; Snowling, Goulandris, \& Defty, 1996; Sprenger-Charolles \& Serniclaes, 2003; Sprenger-Charolles et al., 2012; Ziegler \& Goswami, 2005). Results from these studies generally indicate a phonological awareness deficit in dyslexic readers compared with age-matched controls, to reading-age-matched controls, or both, and this deficit increases over time.

In comparison, fewer studies have been concerned with graphophonological processes, whether at the grapheme or the syllable level. Graphophonemic processes have been studied mainly using a pseudo-word reading aloud task. Although this task is thought to illustrate grapheme-phonemes correspondences, it does not force subjects to process the items at the graphemic level since assembling can be done based of the identification of syllables. Marinus and de Jong (2008) and de Jong and van der Leij (2003) found that dyslexic readers are slower and less accurate than age-matched controls (CA). Casalis (2003) reached the same conclusions comparing dyslexics to reading-age matched controls (RA). As for Griffiths and Snowling (2001), they compared dyslexic readers to a group of normal readers of the same age and a group of the same reading level. Their results indicated that dyslexic readers scored lower than the RA group, which was less accurate than the CA group in reading pseudo-words. With a similar-different paradigm, Fox (1994) presented pairs of words visually (v) and orally (o). Four experimental conditions were set: $\mathrm{v}-\mathrm{v}, \mathrm{v}-\mathrm{O}, \mathrm{O}-\mathrm{v}, \mathrm{o}-\mathrm{o}$. Subjects had to say whether the two words were or were not the same. Results indicated that dyslexics were slower and less accurate than the CA group. They had specific difficulties in the $\mathrm{v}-\mathrm{O}$ or the $\mathrm{o}-\mathrm{v}$ conditions, indicating that grapheme-phoneme or phoneme-grapheme correspondences were more difficult for dyslexics than for the control group. We found only two studies had focused on investigating graphosyllabic processes in dyslexic readers (Colé \& Sprenger-Charolles, 1999; Maïonchi-Pino, Magnan, \& Ecalle, 2010a). With a priming paradigm, subjects had to read a word proceeded by a letter sequence that did or did not correspond to the first syllable of the word. A syllabic effect would have been shown if a facilitation effect had been observed when the prime corresponded to the first syllable. Colé and Sprenger-Charolles (1999) failed to find such an effect in their dyslexic subjects, but Maïonchi-Pino et al. (2010a) did. In this last study, dyslexic subjects used syllables as a reading unit and were faster than reading-age controls, although slower than age-matched controls. None of those studies considered making tasks vary in terms of constraints when investigating specific written units.

\section{Considerations and predictions}

Studying graphophonemic processes is important for determining whether readers can rely on basic processes to access word meaning. In alphabetic languages like English or French, these processes are likely to involve sublexical units of words. Some consideration must, 
however, guide these studies, especially if they are conducted in special populations like dyslexic children. First, it seems important to create tasks that will really target the graphophonological processes under investigation. One wants to make sure that subjects truly process items at one level only, whatever the unit involved. Second, it appears relevant to evaluate more than one process, for example, graphophonemic and graphosyllabic processes. Considering that much emphasis is put on grapheme-phoneme correspondences in reading instruction, we could predict that graphophonemic processes would be better mastered by beginning readers than graphosyllabic processes. Third, results from previous studies suggest the relevance of considering accuracy and response latency as variables. For SprengerCharolles and Serniclaes (2003), in order to better comprehend results obtained in dyslexic studies, success rates are not sufficient and reaction time must also be accounted for in the interpretation of results. Within the context of a longitudinal study, we could expect, for example, that less proficient readers might progress both on accuracy and response time while more proficient readers would show progress on response latency only. Fourth, when studying disabled readers, it is important to consider two control groups. For Casalis (2003), in order to define whether dyslexic readers have a delay or a deviant developmental path, it is important to compare them with two groups of normal readers. In a case where dyslexic performance is weaker than that of normal readers of the same age but at the same level as that of normal younger readers, dyslexic readers could be considered delayed. However, if their performance is worse than that of both groups, then we would have to consider the presence of a deviant path. This would have implications not only for research, but also for remedial measures implemented to help dyslexic children, for example, by creating specific training programs favoring the development of targeted compensatory processes. Lastly, taking into consideration studies of phonological awareness that have shown differences based on task requirements (Bialystok, 2001; Gombert, 1992; Lecocq, 1991; Yopp, 1988), we can expect readers to process the graphemic or the syllabic structures of written items with more ease when fewer cognitive constraints are attached to the tasks. Studies of graphophonological processes have used tasks that do not explicitly ask subjects to manipulate the written (graphemic or syllabic) structure of items. For example, read-aloud protocols, with or without priming or the illusory conjunctions paradigm, do not explicitly ask subjects to process the written units corresponding to the oral phonological structure of words, even though that is what is expected from them.

In our longitudinal study of graphophonological processes in dyslexic readers, we predict main effects of participant group, time of data collection, and task constraint. We also predict interaction between variables. Indeed, because of the persistent phonological deficit that dyslexic readers are acknowledged do have, we expect dyslexic readers to show less progress over time than controls groups, especially in the more demanding tasks.

\section{The present study}

This study falls within the framework of research addressing the role of phonological processing, more specifically, of graphophonological processes, in dyslexic readers. The main goal was to study graphophonemic and graphosyllabic processes over a 1-year period in dyslexic readers compared with a RA and a CA group of normal readers using tasks varying in their level of cognitive constraint. Two experiments were developed, one to evaluate graphophonemic processes and one for graphosyllabic processes. In each experiment, two tasks varying in complexity were created, each task targeting a specific written unit in French (grapheme or syllable). In the awareness- tasks, subjects were not required to explicitly process the written units. In the awareness + tasks, instructions forced subjects to 
process the written units under investigation. Results from both experiments will be interpreted in the general discussion.

\section{Experiment 1: graphophonemic processes}

This experiment aimed at investigating a process central to reading acquisition, one that asks readers to make correspondences between graphemes and phonemes.

\section{Participants}

Dyslexic participants $(n=20)$ had all been diagnosed by professionals (speech therapists and psychologists) with deep dyslexia. All spoke French as their first language, and they were all enrolled in French-language schools in Quebec (Canada). None of the dyslexic participants had another diagnosed deficit. They were recruited through schools known for having dyslexic children and through dyslexic associations. All dyslexic children had received remediation services over the years. All received parental approval before testing. Dyslexic participants were on average 11.2 years old $(\mathrm{SD}=1.05)$ and were at the reading level of 8.87-year-old normal readers according to the reading comprehension sub-test of the K-ABC battery (Kaufman \& Kaufman, 1993). Dyslexic participants (DYS) were matched at the beginning of the study to normal readers of the same reading level (RA, $n=26$ ) and to normal readers of the same chronological age $(\mathrm{CA}, n=24)$. All control participants spoke French as their first language and were enrolled in the French-language educational system. They were recruited in the Montreal area and had also received parental approval before testing. All participants were tested for general cognitive abilities with the Raven matrices (Raven, 1998). No participant had to be excluded from data analysis based on the results on this measure. Participant characteristics are shown in Table 1.

In order to verify the matching of the groups and the stability of the data over time, we first conducted an ANOVA on chronological age with time (T1, T2) and group (DYS, RA, $\mathrm{CA})$ as the independent variables. Results indicated a main effect of time, $F(1,67)=2043.77$, $p<.001$, a main effect of group, $F(2,67)=101.09, p<.001$, and no interaction between time and group, $F(2,67)=1.77$, ns. Independent of the time of the data collection, dyslexic participants were the same age as the age-matched controls and older than the readinglevel controls $(p<.001)$. A second ANOVA for reading level with time (T1, T2) and group (DYS, RA, CA) as the independent variables revealed a main effect of time, $F(1,67)=64.82$, $p<.001$, a main effect of group, $F(2,67)=37.73, p<.001$, and a Time $\times$ Group interaction, $F$ $(2,67)=10.18, p<.001$. Post-hoc local analyses indicated that, whether at Time 1 or Time 2, dyslexic participants read at the same level as the reading-level controls but had lower scores

Table 1 Participant characteristics

\begin{tabular}{llll}
\hline Participants & Time & Age in years (SD) & Reading level in years (SD) \\
\hline DYS $(n=20)$ & 1 & $11.20(1.05)$ & $8.88(1.41)$ \\
& 2 & $12.36(1.01)$ & $10.36(1.55)$ \\
RA $(n=26)$ & 1 & $7.81(0.85)$ & $8.88(1.32)$ \\
& 2 & $8.89(0.89)$ & $10.41(1.57)$ \\
CA $(n=24)$ & 1 & $11.19(1.04)$ & $12.03(0.96)$ \\
& 2 & $12.25(1.01)$ & $12.27(0.64)$ \\
\hline
\end{tabular}


than age-matched controls $(p<.001)$. The interaction indicated that, compared with dyslexics and reading-level controls whose reading scores significantly improved from Time 1 to Time 2 (in both cases, $p<.001$ ), this was not the case for age-matched controls who scored at ceiling. ${ }^{1}$

\section{Experimental material}

Two computerized experimental tasks were created: one task required less explicit processing (graphophonemic awareness - task $(\mathrm{GP}-)$ ) and one task required participants to more consciously process graphemic units (graphophonemic awareness + task $(\mathrm{GP}+)$ ). In both cases, the material was composed of pseudo-words to ensure that the written material was processed at a sublexical level and to control for potential lexical knowledge that might vary from one population to another.

The GP- task (see Appendix 1) is inspired by Transler, Leybaert, and Gombert (1999) and was used in previous work (Daigle \& Armand, 2008; Daigle, Ammar, Bastien, \& Berthiaume, 2010a). This task is a similarity judgment task requiring participants to determine which of two items (*tauponir ${ }^{2}$ or teuponir) most nearly resembles a target item (toponir). The instructions did not ask participants to explicitly process the graphemic structure of items, but no other processes could lead to the expected answers. In the example above, subjects had to segment items at the graphemic level, activate a phonological representation for each grapheme, and find the homophone of the target $(/ \mathrm{o} / \mathrm{and} / \mathrm{au} / \mathrm{are}$ homophones). The task comprised 36 triplets of pseudo-words. In half of the cases, the target grapheme required an analysis of consonants; in the other half, it required an analysis of vowels. Comparison items had the same number of letters, and orthographical resemblance was controlled for. The target item was always in the center of the top part of the screen. Comparison items (response choices) were placed in the lower part of the screen, one on the left and one on the right. In half of the cases, the expected answer was the item on the left; in the other half, it was the item on the right. All trials were randomized.

Previously used with a different population of disabled readers (Daigle et al., 2010a), the $\mathrm{GP}+$ task (see Appendix 2) is a task asking participants to determine which of four items is the odd one. This task requires subjects to pick the item out of four pseudo-words that starts with a different sound (*calime, cirone, cépale, sanire). Contrary to the GP- task, this task requires subjects to segment the first grapheme of each item and compare them in order to find the one that does not sound the same. One other constraint that is part of this task is that four items, and not three as in the GP- task, need to be processed. This increased processing workload is thought to alter success rate and/or response latency. Forty quadruplet trials were created. All required analysis of consonants. Items of one quadruplet shared the same number of letters, and phonological and orthographical resemblances were controlled for. Only the phonological value of the first grapheme allowed participants to choose the expected item. For each quadruplet, items were placed side by side. The correct responses were found equally in all four positions. All trials were randomized.

\section{Procedures}

All participants were tested 2 years in a row in the winter. The data collection involved more than the tasks reported here, allowing testing on different days for the GP- and the GP+ tasks.

\footnotetext{
${ }_{1}^{1}$ The reading comprehension test of the K-ABC battery reaches ceiling at 12.5 years.

${ }^{2}$ The asterisk always indicates the expected answer.
} 
Both experimental tasks were computerized with LEA software (Bastien, 2002). This software allows automatic gathering of success rates and response time. Participants were met individually in a quiet room, and tasks were presented on a portable computer. For the GP- task, participants were told they would see one pseudo-word at the top of the screen and two at the bottom. After reading the three items, they were to select the item at the bottom of the screen that most nearly resembled the one at the top of the screen. To answer, participants had to press one of the two predefined keys on the keyboard. For the GP+ task, participants were told they would see four pseudo-words on the screen and were asked to choose the item that started with a different sound. To answer, participants had to press one of the four predefined keys on the keyboard. The order of the keys respected the visual order of the four items.

For both tasks, trials always maintained the same presentation. Items of each trial appeared at once and stayed on the screen until either the subjects answered or for a maximum of 10,000 ms. The character series XXXX then appeared and remained for $1,000 \mathrm{~ms}$, followed by another trial. The experimental material was grouped into five trials, and an unlimited pause was planned between each group of trials. The subjects controlled the length of the pause by pressing the spacebar. Each task started with five practice trials.

The following statistical procedures were used. First, given the limited response choices, success rates were evaluated for difference from chance with Student's $t$ test. Second, to verify predictions, ANOVAs were run with scores and response latency on correct responses as the dependent variables. ANOVAs were always conducted with two within-subject factors corresponding to time of data collection (Time 1, Time 2) and task (GP-, GP+) and one between-subjects factor, participant group (DYS, RA, CA), followed, if necessary, by post hoc pairwise group comparisons. Whenever interactions were found, local analyses were done after fixing alternately the other factor (or factors) using Bonferroni correction with a significant threshold of 5\%. Analyses were done with SPSS, version 19. The fact that participants had to choose between two possible responses in the GP- task and four responses in the GP+ task was not considered a problem for comparing success rates since this was one way to increase the cognitive constraint, in addition to the specific instructions linked to each task. However, the comparison of response latency was not directly possible because subjects had to read three items in the GP- task and four items in the GP+task. Comparisons were thus carried out on adapted response latencies after response times for correct answers were divided by three for the GP- task and by four for the GP+ task.

\section{Results}

Analysis of success rates

First, we estimated whether results (see Table 2) were significantly different from chance ( $50 \%$ for the GP- task, $25 \%$ for the GP+ task) using Student's $t$ test. All results were significantly different from chance $(p<.001$ in all cases).

The results of the ANOVA indicated a main effect of group, $F(2,65)=13.227, p<.001$; a main effect of time, $F(1,65)=25.881, p<.001$; and a main effect of task, $F(1,65)=124.01$, $p<.001$. An interaction between group and time was found, $F(2,65)=3.33, p<.05$, and an interaction between group and task was also revealed, $F(2,65)=9.87, p<.001$. No interaction between time and task and no three-way interaction for the factors group, time, and task was found, respectively, $F(1,65)=2.80, n s$, and $F(2,65)=1.88$, $n s$. Considering that the factor group was involved in two different interactions, local analyses will be reported as if there had been a Group $\times$ Time $\times$ Task interaction. 
Table 2 Success rates (\%) and SD on GP tasks, for participant group, and time

\begin{tabular}{|c|c|c|c|c|c|}
\hline \multirow[t]{2}{*}{ Group } & \multirow[t]{2}{*}{ Time } & \multicolumn{2}{|l|}{ GP- } & \multicolumn{2}{|l|}{ GP+ } \\
\hline & & Mean score & SD & Mean score & SD \\
\hline \multirow[t]{2}{*}{ DYS } & 1 & 85.54 & 16.66 & 39.63 & 24.43 \\
\hline & 2 & 93.74 & 6.67 & 45.38 & 26.65 \\
\hline \multirow[t]{2}{*}{ RA } & 1 & 85.47 & 16.37 & 50.77 & 29.43 \\
\hline & 2 & 93.70 & 9.52 & 64.17 & 28.14 \\
\hline \multirow[t]{2}{*}{$\mathrm{CA}$} & 1 & 95.94 & 11.78 & 75.31 & 21.50 \\
\hline & 2 & 94.20 & 12.46 & 83.23 & 16.61 \\
\hline
\end{tabular}

At Time 1, in the GP- task, DYS success rates were not different from those of RA or CA, but RA performed worse than CA $(p<.05)$. In the GP+ task, at Time 1, DYS and RA were not different from one another, but both groups obtained lower scores than $\mathrm{CA}(p<.001$ and $p<.01)$. At Time 2 , in the GP- task, all three groups had comparable performances. In the GP+ task, however, DYS did worse than both RA and CA $(p<.05$ and $p<.001)$, and RA also obtained lower scores then CA $(p<.05)$. Addressing the effect of task, local analyses indicated that accuracy scores were higher on the GP- task than on the GP+ task for all groups at both times $(p<.001$, except for CA at Time 2, $p<.05)$. Finally, with respect to subjects' progress over time, local analyses indicated that DYS success rates improved in the GP - task only $(p<.01)$, while RA made progress on both tasks $(p<.001$ in both cases) and CA became better only in the GP+ task $(p<.05)$.

Analysis of response latency

First, as stated earlier, response times were transformed in order to be comparable due to the unequal number of items to be read. Table 3 presents mean response latency on correct responses only for each task and takes into account time and participant group.

The ANOVA indicated a main effect of group, $F(2,65)=24.93, p<.001$; a main effect of time, $F(1,65)=46.64, p<.001$; and a main effect of task, $F(1,65)=62.49, p<.001$. No interaction between group and time or between time and task was found, $F(2,65)=0.64$, $n s$ and $F(1,65)=3.45, n s$, but an interaction between group and task was revealed, $F(2,65)=$ $9.63, p<.001$, and a Group $\times$ Time $\times$ Task interaction was also found, $F(2,65)=7.93, p<.001)$.

Table 3 Mean response latency (milliseconds) on GP tasks for participant group and time

\begin{tabular}{|c|c|c|c|c|c|}
\hline \multirow[t]{2}{*}{ Group } & \multirow[t]{2}{*}{ Time } & \multicolumn{2}{|l|}{ GP- } & \multicolumn{2}{|l|}{ GP+ } \\
\hline & & Mean latency & SD & Mean latency & SD \\
\hline \multirow[t]{2}{*}{ DYS } & 1 & 1414.95 & 466.96 & 1585.54 & 305.39 \\
\hline & 2 & 1225.63 & 385.53 & 1313.16 & 300.50 \\
\hline \multirow[t]{2}{*}{ RA } & 1 & 1487.38 & 511.65 & 1579.94 & 195.38 \\
\hline & 2 & 1115 & 434.99 & 1573.23 & 225.29 \\
\hline \multirow[t]{2}{*}{$\mathrm{CA}$} & 1 & 801.21 & 322.72 & 1329.47 & 246.55 \\
\hline & 2 & 655.31 & 204.98 & 1169.22 & 212.39 \\
\hline
\end{tabular}


Pairwise comparisons indicated at Time 1, in the GP-, and the GP+ tasks that DYS and RA response latencies were slower than those of CA ( $p<.01$ in all cases), but DYS and RA were not different one from the other. Similarly, at Time 2, on the GP- task only, DYS and RA, which were not different, were slower than CA $(p<.001$ in both cases). However, in the GP+ task at Time 2, DYS was faster than RA $(p<.01)$ and did not differ in response latency compared with CA. RA was also slower than CA. Looking at the effect of task, local analyses at Time 1 indicated that DYS and RA had similar response latencies on both tasks, while CA was faster on the GP- task compared with the GP+task $(p<.001)$. At Time 2, DYS had equivalent response latencies whatever the task. RA and CA, however, responded more quickly on the GP- task than on the GP+ task ( $p<.001$ in both cases). Finally, results of differences in response latencies over time indicated for DYS a reduction in response latencies on the GP- and GP+ tasks (respectively, $p<.05$ and $p<.001$ ). In RA subjects, this was the case only in the GP- task $(p<.001)$ and, in CA participants, only in the GP+ task $(p<.01)$.

\section{Experiment 2: graphosyllabic processes}

This second experiment also aimed at investigating graphophonological processes through the study of graphosyllabic analysis. In this experiment, it is the structure of syllables that needs to be processed. In French, liquid consonants may be used alone or be followed by another consonant. Alone, a liquid constitutes the coda of a first syllable ("r" in marteaul hammer). When a liquid is preceded by another consonant, the two together create a complex onset of a second syllable ("r" in patron/boss). Thus, except for double liquids, the orthographic environment of liquid consonants determines the syllable to which they belong and whether the two consonants are part of the same syllable (the letters "rt" in marteau are not part of the same syllable, but the letters "tr" in patron are). Predictions are the same as those made for the entire study as presented earlier.

\section{Participants}

Participants were the same as those in Experiment 1.

Experimental material

Two computerized graphosyllabic tasks were used, one graphosyllabic awareness- task (GS-) and one graphosyllabic awareness + task (GS+). Tasks were designed according to the same principles described in Experiment 1. In both cases, only pseudo-words were used.

Inspired by Transler, Leybaert, and Gombert (1999), the GS- task is a similarity judgment task similar to the task used in other studies (e.g., Daigle \& Armand, 2008 and Daigle, Ammar, Bastien, Berthiaume, \& Besse, 2010b). This task requires subjects to select from two comparison pseudo-words the one that most nearly resembles a target pseudoword. The instructions given to subjects (e.g., Which of carbi or *cabri most nearly resembles capli?) do not require explicit processing of the syllable structure of the items to be read. However, only the syllabic structure can lead to the selection of the expected item. In the example above, subjects cannot rely on graphophonemic processes or on orthographic processes to find the expected answer. They need to segment the items into syllables, CVC-CV vs CV-CCV, activate the phonological representation of each syllable, and find the item that shares the same structure at the phonological level with the target item. The experimental material was made up of 40 triplets of pseudo-words (see Appendix 3). Pseudo-words of the same triplet had the same number of letters and syllables. Half of the 
target items had a liquid-consonant sequence (L/C, morpa); the other half, a consonantliquid sequence (/CL, mapli). The target item was always placed in the center of the upper third of the computer screen. The two comparison items were placed in the lower third of the screen, one on the left and one on the right. The position of the expected items was randomly selected, but half of the correct responses appeared as the left item and half as the right item. All trials were randomized.

On the GS+ task, participants had to locate the odd item out of four items (see Appendix4). This task had previously been used in Daigle et al. (2010b). This type of task is frequently used in phonological awareness studies. In this task, participants were asked to select the item that started with a syllable of a different structure from that of the other items (e.g., baflo*, barto, balpé, barfi). All the first syllables had the two first letters in common. In contrast to the GStask, the instructions (Which item begins with a different syllabic structure?) and the orthographical similarities between first syllables in each trial required participants to manipulate explicitly the syllabic structure of the items being read. In contrast to the GS- task, four items needed to be analyzed, increasing the constraint attached to this task. The experimental material was made up of 40 trials. Pseudo-words in each trial had an equal number of letters and syllables. Items in each trial were controlled for phonological and orthographical similarities. Half of the trials targeted a L/C structure and half a /CL structure. The four items were located in a row in the middle of the computer screen. The position of the expected response was randomly chosen, but, in total, an equal number of expected responses was ensured for each of the four possible positions. All trials were randomized.

Procedures

Procedures were the same as the ones described for Experiment 1. Similarly, the GS- task and the GS+ task were administered on different days.

\section{Results}

Analysis of success rates

As in the first experiment, we first determined, using Student's $t$ test, whether results (see Table 4) were significantly different from chance ( $50 \%$ for the GS - task, $25 \%$ for the GS+ task). All results differed significantly from chance ( $p<.01$ for DYS, and $p<.001$ in the case of RA and CA).

Results of the ANOVA indicated a main effect of group, $F(2,67)=12.04, p<.001$; a main effect of time, $F(1,67)=17.29, p<.001$; and a main effect of task, $F(1,67)=27.75, p<.001$. No interaction between group and time, group and task, or between time and task were found, respectively, $F(2,67)=1.14, n s ; F(2,67)=2.22$, $n s$; and $F(1,67)=0.57$, $n s$. However, a three-way interaction for the factors group, time, and task was found, $F(2,67)=3.24, p<.05$.

Local analyses of the GS- task indicated at Time 1 and at Time 2 that DYS success rates did not differ from those of RA but were lower than those of CA $(p<.001$ in both cases). At both times, RA also performed worse than CA $(p<.01)$. A similar pattern was observed on the GS + task at Time 1 only, where DYS did not differ from RA but obtained lower scores than CA $(p<.001)$, and RA also scored less than CA $(p<.05)$. However, on the GS+ task at Time 2, DYS success rate did not differ from RA or CA, while RA still performed less well than CA $(p<.01)$. Regarding task effect, analyses at Time 1 indicated that DYS and RA obtained higher scores for the GS- task than for the GS+ task $(p<.01$ in both cases). CA scores did not differ significantly between tasks at Time 1. At Time 2, DYS and CA accuracy 
Table 4 Success rates (\%) and SD on GS tasks, for participant group, and time

\begin{tabular}{|c|c|c|c|c|c|}
\hline \multirow[t]{2}{*}{ Group } & \multirow[t]{2}{*}{ Time } & \multicolumn{2}{|l|}{$\mathrm{GS}-$} & \multicolumn{2}{|l|}{$\mathrm{GS}+$} \\
\hline & & Mean score & $\mathrm{SD}$ & Mean score & $\mathrm{SD}$ \\
\hline \multirow[t]{2}{*}{ DYS } & 1 & 61.75 & 14.15 & 43.38 & 22.82 \\
\hline & 2 & 66.13 & 20.48 & 61.63 & 30.48 \\
\hline \multirow[t]{2}{*}{ RA } & 1 & 65.87 & 16.45 & 50.58 & 28.39 \\
\hline & 2 & 73.85 & 20.91 & 52.60 & 29.44 \\
\hline \multirow[t]{2}{*}{$\mathrm{CA}$} & 1 & 81.15 & 14.96 & 74.58 & 21.62 \\
\hline & 2 & 87.40 & 13.60 & 80.21 & 23.07 \\
\hline
\end{tabular}

did not differ in terms of task. RA, however, still obtained higher scores on the GS - task than on the GS+ task $(p<.001)$. Finally, analyses indicated that DYS did not progress from Time 1 to Time 2 on the GS - task but did on the GS+ task $(p<.001)$. RA progressed only on the GS - task $(p<.05)$, and CA accuracy scores did not differ from Time 1 to Time 2 on either task.

\section{Analysis of response latency}

Table 5 presents mean response latency (after transformation as in Experiment 1) on correct responses only for each GS task.

The ANOVA revealed a main effect of group, $F(2,67)=12.22, p<.001$; a main effect of time, $F(1,67)=23.68, p<.001$; and a main effect of task, $F(1,67)=14.02, p<.001$. No interaction between group and time was found, $F(2,67)=0.22$, $n s$. An interaction between group and task as well as between time and task were present, $F(2,67)=5.68, p<.01$ and $F$ $(1,67)=5.28, p<.05$. No Group $\times$ Time $\times$ Task interaction was found, $F(2,67)=0.92, n s$. Considering that the task variable was involved in two different interactions, local analyses will be reported as if there had been a Group $\times$ Time $\times$ Task interaction.

Pairwise comparisons on the GS- task at Time 1 and at Time 2 indicated that DYS did not differ from RA on response latencies but was slower than CA $(p<.01$ at both times). RA was also slower than CA at both times $(p<.01)$. On the GS+ task at Time 1 and at Time 2, DYS mean response rates did not differ from RA or CA, while RA was slower than CA at Time 2 only $(p<.05)$. Local analyses at Time 1 for the effect of task indicated that DYS and

Table 5 Mean response latency (milliseconds) on GS tasks for participant group and time

\begin{tabular}{|c|c|c|c|c|c|}
\hline \multirow[t]{2}{*}{ Group } & \multirow[t]{2}{*}{ Time } & \multicolumn{2}{|l|}{ GS- } & \multicolumn{2}{|l|}{ GS+ } \\
\hline & & Mean latency & SD & Mean latency & SD \\
\hline \multirow[t]{2}{*}{ DYS } & 1 & 1571.92 & 541.82 & 1564.90 & 487.08 \\
\hline & 2 & 1345.05 & 445.25 & 1442.24 & 329.93 \\
\hline \multirow[t]{2}{*}{ RA } & 1 & 1686.45 & 486.29 & 1627.63 & 337.78 \\
\hline & 2 & 1324.60 & 420.86 & 1514.31 & 347.84 \\
\hline \multirow[t]{2}{*}{$\mathrm{CA}$} & 1 & 1098.65 & 377.82 & 1403.81 & 287.68 \\
\hline & 2 & 876.54 & 340.22 & 1246.34 & 292.13 \\
\hline
\end{tabular}


RA response latencies did not differ according to task. CA, however, was faster on GS- than on GS+ $(p<.001)$. At Time 2 , there was no difference in response latency according to task in DYS. But, RA and CA responded faster on the GS - task than on the GS+ task $(p<.05$ and $p<.001$, respectively). Finally, results of analyses of differences in response latencies over time indicated that DYS, RA, and CA responded faster over time only on the GS- task (respectively, $p<.05, p<.001$, and $p<.05$ ). No significant changes were observed over time on the GS+ task for response latency.

\section{General discussion}

This study aimed to investigate phonological processing in dyslexic readers through the analysis of graphophonological processes. Results indicate that dyslexic readers, like their control counterparts, do process phonological information involved in written processes at the graphemic and syllabic level. Indeed, all results were above the chance boundary mark. Because of the methodological choices made when this study was created, it was obvious that results could not be clear-cut and would show interactions between variables. Indeed, choosing to collect longitudinal data with tasks that were not expected to create similar patterns of results in populations who typically behave differently made this study both challenging and interesting. According to predictions we made, we were expecting main effects of participant group, time of data collection, and task constraint. Although with some nuances, results we obtained conform to these predictions.

First, following others who have considered the importance of two control groups (Sprenger-Charolles \& Colé, 2003; Casalis, 2003) and given the mixed empirical results for group comparisons (e.g., Bosse \& Valdois, 2003; Manis et al., 1993; Maïonchi-Pino et al, 2010b), we predicted group differences, where dyslexics would either perform like readingage peers, showing a delay in dyslexics, or perform differently from both control groups, pointing to a deviant developmental path (Casalis, 2003). The results obtained in this study did not fit either explanation. In the first experiment, results may point to a deviant path since dyslexics are particularly impeded over time compared with reading-level controls and agematched controls in the more demanding task $(\mathrm{GP}+)$. However, in the graphosyllabic experiment, dyslexics attained at the end of the study the level of age-matched controls in the task that required more attention. Results of the second experiment alone cannot be viewed as an indication of a deviant path. We need to consider results from both experiments to arrive at this conclusion. Indeed, graphosyllabic processes could be considered as compensatory processes used in dyslexics in order to bypass their difficulty at the graphemic level. This may in part explain why dyslexics with the same reading level as the younger normal readers get lower scores on graphophonemic processes. This may indicate that both written units are not processed the same way, reminiscent of results from phonological awareness studies where phonemic awareness is mastered later than syllabic awareness (for a review, see Demont \& Gombert, 2007). We argue that the syllable is more accessible than grapheme for dyslexic children, and that, over time, they increase their ability to extract regularities related to the syllabic structures of words from written material. Indeed, because written syllables can be processed through analysis of their phonological structure or the phonological and orthographical structures, dyslexic children may rely more heavily on the orthographic properties of the syllables to extract regularities. For example, in our graphosyllabic task, even if expected responses were only detectable through phonological processing, syllabic structures differed based on the liquid consonants present. Yet, except for double consonants, only the letters " $\mathrm{L}$ " and "T" and their position with respect to the 
adjacent consonant determine the syllabic structure of written items. This limited orthographic context may favor the extraction of rules, even when they are not explicitly taught in class (see for example, Pacton, Perruchet, Fayol, \& Cleeremans, 2001, for a discussion on implicit learning of orthographic regularities through reading experience).

Second, with respect to the relevance of longitudinal data (Castles \& Coltheart, 2004; Swanson et al., 2003), we were very interested in discovering whether or not dyslexic readers would progress over time. We predicted differences in results over time. Two indicators of improvement were obtained in this study. Increasingly better scores would imply that subjects had gained knowledge over time or that they were able to apply it better. Decreasing response latency scores would also indicate progress in that they could be the result of a more automatized process requiring less attentional capacity (Segalowitz, 2010), or they could simply be the consequence of more reading experience over time. In light of these indicators, results on accuracy, response latency, or both indicated that all three groups progressed over time in processing both graphemes and syllables. Following Sprenger-Charolles and Serniclaes (2003), we consider that both variables may be essential to better understand developmental reading disorders. In this study, both variables are equally important for explaining improvement over time in dyslexics and their reading-age peers, and response latency seems a better indicator of progress in age-matched controls. Because we considered response latency as a variable, we were able to say, for example, that older normal readers still made progress even after years of reading instruction

Third, inspired by the work done in the field of phonological awareness (Lecocq, 1991; Yopp, 1988), we considered graphophonological tasks varying in the level of awareness required to process the written material. As a consequence, tasks that require less awareness (GP-, GS-) were expected to lead to higher success rates and lower response latencies than tasks requiring more awareness (GP+, GS+). Generally, this is what we observed. However, for the dyslexic participants, the task has an effect on accuracy only. Whatever the constraint of the task, dyslexic participants' response latency did not vary at either time of data collection. This may show that graphophonological processing remain quite laborious in dyslexic readers, even after years of reading experience. These results taken together with those of studies revealing a phonological awareness deficit in dyslexic readers (Bosse \& Valdois, 2003; Casalis, 2003; Demont 2003; Sprenger-Charolles \& Serniclaes, 2003) may indicate that dyslexics not only have a problem with phonological processing, but a specific deficit in explicit phonological processing (Gombert, 1992). Classifying tasks according to their level of constraint seems, therefore, relevant. Additional studies will be needed to confirm this assertion. To date, no other known work has been carried out from this perspective, with the exception of Daigle et al. (2010a) and Daigle et al. (2010b), who reached similar conclusions in another reading delayed population.

In conclusion, results obtained in this study, notably in relation to task type or progress made over time, point to the complexity of graphophonological processing in dyslexic readers. More specifically, they speak to the importance of considering, in future research, both phonological awareness and graphophonological processing as well as their relation to reading development. Indeed, it could be difficult to make clear assertions concerning the developmental path of phonological processing if only phonological awareness has been evaluated. It is not because learners have phonological awareness abilities that they will apply that knowledge automatically when processing written material. Conversely, it is difficult to explain specific difficulties in processing print at the graphophonological level 
without having measured phonological awareness, as was the case in this study. We are conscious of this limitation, while maintaining the importance of testing graphophonological processing. That is why we propose a three-step approach, phonological awareness/graphophonological processing/reading, in studies to come. Not only is such an approach likely to contribute to our understanding of phonological processing, it should also yield contributions that can be applied in intervention guidelines.

Acknowledgments This work was supported by the Social Sciences and Humanities Research Council of Canada (SSHRC) with a grant made to the first author. We would like to extend our gratitude to the participants and research assistants for their invaluable contributions to this study. The first and second authors are members of the Centre for the Study of Learning and Performance (CSLP).

\section{Appendix}

Table 6 Graphophonemic awareness- task (GP-): some examples

Table 7 Graphophonemic awareness + task $(\mathrm{GP}+)$ : some examples
Phonemes' orthographic Position in pseudo-words representations

\begin{tabular}{|c|c|c|c|}
\hline & Position1 & Position2 & Position 3 \\
\hline & « toponir $»$ & « pinome » & « barcelo » \\
\hline \multirow[t]{3}{*}{ [o]:(o) } & tauponir & pinaume & barcelau \\
\hline & teuponir & pineume & barceleu \\
\hline & « daufiré » & « filauper » & « limanau » \\
\hline \multirow[t]{3}{*}[\mathrm{o}]{$:(\mathrm{au})$} & dofiré & filoper & limano \\
\hline & difiré & filiper & limani \\
\hline & « assépone » & « rassiper » & « laubisser » \\
\hline \multirow[t]{3}{*}{ [s]:(ss) } & acépone & raciper & laubicer \\
\hline & agépone & ragiper & laubiger \\
\hline & 《 acidème » & « bacemer » & « raloucie $»$ \\
\hline \multirow[t]{2}{*}[\mathrm{s}]{$:(\mathrm{c})$} & assidème & bassemer & raloussie \\
\hline & annidème & bannemer & ralounnie \\
\hline
\end{tabular}

\begin{tabular}{lll}
\hline $\begin{array}{l}\text { Target } \\
\text { phoneme }\end{array}$ & Experimental items & $\begin{array}{l}\text { Position of the } \\
\text { expected answer }\end{array}$ \\
\hline$[\mathrm{k}]$ & calime cirone cépale sanire & 1 \\
{$[\mathrm{k}]$} & césani catamo saripé cidomu & 2 \\
{$[\mathrm{k}]$} & safiro cizalé cavumé célani & 3 \\
{$[\mathrm{k}]$} & cipolé céréli sumanu cotéla & 4 \\
{$[\mathrm{~s}]$} & cékane cavène codile cutare & 1 \\
{$[\mathrm{~s}]$} & copano céropi cumani cafiré & 2 \\
{$[\mathrm{~s}]$} & curolé camisu céniro cosuma & 3 \\
{$[\mathrm{~s}]$} & codane cutule cafire cirème & 4
\end{tabular}


Table 8 Graphosyllabic awareness- task (GS-): some examples

Condition*/CL* condition

\begin{tabular}{|c|c|c|c|}
\hline \multicolumn{2}{|c|}{ Two-syllables items } & \multicolumn{2}{|c|}{ Three-syllables items } \\
\hline « nibra » & « capli » & « mutabli » & « javoplé » \\
\hline nifla & cabri & mutafri & javobré \\
\hline nilfa & carbi & mutarfi & javorbé \\
\hline « dopré » & « faglu» & « gidobra » & 《 sénucro » \\
\hline doclé & fapru & gidocla & sénublo \\
\hline dolcé & farpu & gidolca & sénulbo \\
\hline \multicolumn{4}{|c|}{ Condition ${ }^{*} \mathrm{~L} / \mathrm{C}^{*}$ condition } \\
\hline « vorba » & «forpa $»$ & « fimirba » & « fimirba » \\
\hline volga & folga & fimilpa & fimilpa \\
\hline vogla & fogra & fimipla & fimipla \\
\hline « nilbi » & « salbo » & « nabolta » & « novalbé » \\
\hline nirpi & sarfo & naborca & novarpé \\
\hline nipri & safro & nabocra & novapré \\
\hline
\end{tabular}

Table 9 Graphosyllabic awareness + task (GS+): some examples

\begin{tabular}{lll}
\hline Syllabic structure targeted & Experimental items & Position of the expected answer \\
\hline CV & baflo barto balpé barfi & 1 \\
CV & balpo bapré baldé barni & 2 \\
CV & balnu barco bacla barfa & 3 \\
CV & balsu barna baldo badru & 4 \\
CVC & barco baplo bafri baclu & 1 \\
CVC & badri baldé bagré bablu & 2 \\
CVC & batré bablo barbo baglo & 3 \\
CVC & bacru bapla batro baltu & 4 \\
\hline
\end{tabular}

\section{References}

Adam, M. J. (1990). Beginning to read: Thinking and learning about print. Cambridge, MA: MIT Press.

Anthony, J. L., \& Lonigan, C. J. (2004). The nature of phonological awareness: Converging evidence from four studies of preschool and early grade school children. Journal of Educational Psychology, 96(1), 4355. doi:10.1037/0022-0663.96.1.43.

Bastien, M. (2002). LÉA: Le logiciel d'évaluation des apprentissages. Montréal: Université du Québec à Montréal, Département de linguistique et de didactique des langues.

Bialystok, E. (2001). Bilingualism in development. Language, literacy, \& cognition. New-York: Cambridge University Press.

Bosse, M.-L., \& Valdois, S. (2003). Patterns of developmental dyslexia according to a multi-trace memory model of reading. Current Psychology Letters, 10(1). Retrieved from http/cpl.revues.org/ index $92 . h t m 1$. 
Caravolas, M., \& Landerl, K. (2010). The influences of syllable structure and reading ability on the development of phoneme awareness: A longitudinal, cross-linguistic study. Scientific Studies of Reading, 14(5), 464-484. doi:10.1080/10888430903034804.

Casalis, S. (2003). The delay-type in developmental dyslexia: Reading processes. Current Psychology Letters, 10(1). Retrieved from http/cpl.revues.org/index 95.html.

Castles, A., \& Coltheart, M. (2004). Is there a causal link from phonological awareness to success in learning to read? Cognition, 91(1), 77-111. Retrieved from http://linkinghub.elsevier.com/retrieve/pii/ S0010027703001641.

Colé, P., Magnan, A., \& Grainger, J. (1999). Syllable-sized units in visual word recognition: Evidence from skilled and beginning readers of French. Applied psycholinguistics, 20(4), 507-532. Retrieved from http:// journals.cambridge.org/abstract_S0142716499004038.

Colé, P., \& Sprenger-Charolles, L. (1999). Traitement syllabique au cours de la reconnaissance de mots écrits chez des enfants dyslexiques, lecteurs en retard et normo-lecteurs de 11 ans. Revue de neuropsychologie, 9(4), 323-360. Retrieved from http://rnp.resodys.org/IMG/pdf/vol9n4_323_360.pdf.

Coltheart, M., Curtis, B., Atkins, P., \& Haller, M. (1993). Models of reading aloud: Dual route and parallel processing approaches. Psychological Review, 100(4), 589-608. doi:10.1037/0033-295X.100.4.589.

Coltheart, M., Rastle, K., Perry, C., Langdon, R., \& Ziegler, J. (2001). DRC: A dual route cascades model of visual word recognition and reading aloud. Psychological Review, 108(1), 204-256. doi:10.1037/0033295X.108.1.204.

Daigle, D., Ammar, A., Bastien, M., \& Berthiaume, R. (2010a). Procédures graphophonologiques chez des lecteurs sourds en français langue seconde. Language Awareness, 19(1), 1-16. doi:10.1080/ 09658410902928487.

Daigle, D., Ammar, A., Bastien, M., Berthiaume, R., \& Besse, A. S. (2010b). Syllabic processing in deaf readers of French as a second language. Deafness and Education International, 12(1), 16-33. doi:10.1179/146431510X12626982043561.

Daigle, D., \& Armand, F. (2008). Phonological sensitivity in severely and profoundly deaf readers of French. Reading and Writing: An Interdisciplinary Journal, 21(7), 699-717. doi:10.1007/s11145-007-9087-5.

de Jong, P. F., \& van der Leij, A. (2003). Developmental changes in the manifestation of a phonological deficit in dyslexic children learning to read a regular orthography. Journal of Educational Psychology, 95(1), 22-40. doi:10.1037/0022-0663.95.1.22.

Demont, E. (2003). Developmental dyslexia and sensitivity to rhymes: A perspective for remediation. Current Psychology Letters, 10(1). Retrieved from http://cpl.revues.org/index380.html.

Demont, E., \& Gombert, J. E. (2007). Relation conscience phonologique \& apprentissage de la lecture: Peuton sortir de la relation circulaire? In E. Demont \& M. N. Metz-Lutz (Eds.), Acquisition du langage: Vers une approche intégrée (pp. 47-79). Marseille: Solal.

Doignon, N., \& Zagar, D. (2006). Les enfants en cours d'apprentissage de la lecture perçoivent-ils la syllabe à l'écrit? Canadian Journal of Experimental Psychology, 60(4), 258-274. doi:10.1037/cjep2006024.

Duncan, L. G., \& Seymour, P. H. K. (2003). How do children read multisyllabic words? Some preliminary observations. Journal of Research in Reading, 26(2), 101-120. doi:10.1111/1467-9817.00190.

Ferrand, L., Segui, J., \& Grainger, J. (1996). Masked priming of word and picture naming: The role of syllabic units. Journal of Memory and Language, 35(5), 708-723. doi:10.1006/jmla.1996.0037.

Fox, E. (1994). Grapheme-phoneme correspondence in dyslexic and matched control readers. British Journal of Psychology, 85(1), 41-53. doi:10.1111/j.2044-8295.1994.tb02507.x.

Gombert, J. E. (1992). Metalinguistic development. London, England: Harvester Wheatsheaf.

Gombert, J. E. (2003). Implicit and explicit learning to read: Implication as for subtypes of dyslexia. Current Psychology Letters, 10(1). Retrieved from http://cpl.revues.org/document202.html.

Goswami, U. (2002). Phonology, reading development, and dyslexia: A cross-linguistic perspective. Annals of Dyslexia, 52(1), 139-163. doi:10.1007/s11881-002-0010-0.

Goswami, U., \& Bryant, P. E. (1990). Phonological skills and learning to read. Hillsdale: Erlbaum.

Griffiths, Y. M., \& Snowling, M. J. (2001). Auditory word identification and phonological skills in dyslexic and average readers. Applied PsychoLinguistics, 22(3), 419-439. doi:10.1017/S0142716401003071.

Hagiliassis, N., Pratt, C., \& Johnston, M. (2006). Orthographic and phonological processes in reading. Reading and Writing, 19(3), 235-263. doi:10.1007/s11145-005-4123-9.

Jongejan, W., Verhoeven, L., \& Siegel, L. S. (2007). Predictors of reading and spelling abilities in first- and second-language learners. Journal of Educational Psychology, 99(4), 835-851. doi:10.1037/00220663.99.4.835.

Kaufman, A. S., \& Kaufman, N. L. (1993). K.ABC. Batterie pour l'examen psychologique de l'enfant. American Guidance Service (French version, 1993 par ECPA).

Kirby, J. R., Desrochers, A., Roth, L., \& Lai, S. S. V. (2008). Longitudinal predictors of word reading development. Canadian Psychology, 49(2), 103-110. doi:10.1037/0708-5591.49.2.103. 
Larkin, R. F., \& Snowling, M. J. (2007). Comparing phonological skills and spelling abilities in children with reading and language impairments. International Journal of Language \& Communication, 43(1), 111124. Retrieved from http://www.ncbi.nlm.nih.gov/pubmed/17852532.

Lecocq, P. (1991). Apprentissage de la lecture et dyslexie. Brussels, Belgium: Mardaga.

Lefrançois, P., \& Armand, F. (2003). The role of phonological and syntactic awareness in second language reading: The case of Spanish-speaking learners of French. Reading and Writing: An Interdisciplinary Journal, 16(3), 218-246. Retrieved from http://www.springerlink.com/content/m21426514m1pp055/.

Maïonchi-Pino, N., Magnan, A., \& Ecalle, J. (2010a). The nature of the phonological processing in French dyslexic children: Evidence for the phonological syllable and linguistic features' role in silent reading and speech discrimination. Annals of Dyslexia, 60(2), 123-150. doi:10.1007/s11881-010-0036-7.

Maïonchi-Pino, N., Magnan, A., \& Ecalle, J. (2010b). Syllable frequency effects in visual word recognition: Developmental approach in French children. Journal of Applied Developmental Psychology, 31(1), 7082. doi:10.1016/j.appdev.2009.08.003.

Manis, F. R., Custodio, R., \& Szeszulski, P. A. (1993). Development of phonological and orthographic skill: A 2-year longitudinal study of dyslexia children. Journal of Experimental Child Psychology, 56(1), 64-86. doi:10.1006/jecp. 1993.1026.

Marinus, E., \& de Jong, P. F. (2008). The use of sublexical clusters in normal and dyslexic readers. Scientific Studies of Reading, 12(3), 253-280. doi:10.1080/10888430802132246.

Pacton, S., Perruchet, P., Fayol, M., \& Cleeremans, A. (2001). Implicit learning out of the lab: The case of orthographic regularities. Journal of Experimental Psychology General, 130(3), 401-426. doi:10.1037// 0096-3445.130.3.401.

Plaza, M., \& Cohen, H. (2003). The interaction between phonological processing, syntactic sensitivity and naming speed in the reading and spelling performance of first-grade children. Brain and Cognition, 53(2), 287-292. doi:10.1016/S0278-2626(03)00128-3.

Prinzmetal, W., Hoffman, H., \& Vest, K. (1991). Automatic processes in word perception: An analysis from illusory conjunctions. Journal of Experimental Psychology: Human Perception and Performance, 17(4), 902-923. Retrieved from http://psycnet.apa.org/journals/xhp/17/4/902.pdf.

Prinzmetal, W., Treiman, R., \& Rho, S. H. (1986). How to see a reading unit. Journal of Memory and Language, 25(4), 461-475. doi:10.1016/0749-596X(86)90038-0.

Rastle, K., \& Coltheart, M. (1998). Whammies and double whammies: The effect of length on nonword reading. Psychonomic Bulletin \& Review, 5(2), 277-282. doi:10.3758/BF03212951.

Raven, J. C. (1998). Progressives Matrices Couleur, Issy-les-Moulineaux, France: Éditions Scientifiques et Psychotechniques.

Rey, A., Jacobs, A. M., Schmidt-Weigand, F., \& Ziegler, J. C. (1998). A phoneme effect in visual word recognition. Cognition, 68(3), B71-B80. doi:10.1016/S0010-0277(98)00051-1.

Rey, A., Ziegler, J. C., \& Jacobs, A. M. (2000). Graphemes are perceptual reading units. Cognition, 75(1), B1-B12. doi:10.1016/S0010-0277(99)00078-5.

Segalowitz, N. (2010). The cognitive bases of second language fluency. New York: Routledge.

Siegel, L. (2003). Basic cognitive processes and reading disabilities. In H. L. Swanson, K. R. Harris, \& S. Graham (Eds.), Handbook of learning disabilities (pp. 158-181). New York: Guilford Press.

Snowling, M. (2000). Dyslexia. Oxford: Blackwell.

Snowling, M. J., Goulandris, N., \& Defty, N. (1996). A longitudinal study of reading development in dyslexic children. Journal of Educational Psychology, 88(4), 653-669. doi:10.1037/0022-0663.88.4.653.

Sprenger-Charolles, L., \& Colé, P. (2003). Lecture et dyslexie: approche cognitive. Paris: Dunod.

Sprenger-Charolles, L., \& Serniclaes, W. (2003). Reliability of phonological and surface subtypes in developmental dyslexia: A review of five multiple cases studies. Current Psychology Letters, 10(1), Retrieved from http://cpl.revues.org/index248.html.

Sprenger-Charolles, L., \& Siegel, L. S. (1997). A longitudinal study of the effects of syllabic structure on the development of reading and spelling skills in French. Applied PsychoLinguistics, 18(4), 485-505. doi:10.1017/S014271640001095X.

Sprenger-Charolles, L., Siegel, L. S., Jiménez, J. E., \& Ziegler, J. (2012). Prevalence and reliability of phonological, surface, and mixed profiles in dyslexia: A review of studies conducted in languages varying in orthographic depth. Scientific Studies of Reading (in press).

Stanovich, K. E. (1990). Concepts in developmental theories of reading skill: Cognitive resources, automaticity, and modularity. Developmental Review, 10(1), 72-100. doi:10.1016/0273-2297(90)90005-O.

Swanson, H. L., Trainin, G., Necoechea, D. M., \& Hammill, D. D. (2003). Rapid naming, phonological awareness, and reading: A meta-analysis of the correlation evidence. Review of Educational Research, 73 (4), 407-440. doi:10.3102/00346543073004407.

Transler, C., Leybaert, J., \& Gombert, J.-E. (1999). Do deaf children use phonological syllables as reading units? Journal of Deaf Studies and Deaf Education, 4(2), 124-143. doi:10.1093/deafed/4.2.124. 
Vellutino, F., Fletcher, J., Snowling, M., \& Scanlon, D. (2004). Specific reading disability (dyslexia): What have we learned in the past four decades? Journal of Child Psychology and Psychiatry, 45(1), 2-40. doi:10.1046/j.0021-9630.2003.00305.x.

Wagner, R. K., Torgesen, J. K., \& Rashotte, C. A. (1994). Development of reading-related phonological processing abilities: New evidence of bidirectional causality from a latent variable longitudinal study. Developmental Psychology, 30(1), 73-87. doi:10.1037/0012-1649.30.1.73.

Whitehurst, G. J., \& Lonigan, C. J. (1998). Child development and emergent literacy. Child Development, 69 (3), 848-872. doi:10.1111/j.1467-8624.1998.tb06247.x.

Yopp, H. K. (1988). The validity and reliability of phonemic awareness tests. Reading Research Quarterly, 23 (2), 159-177. doi:10.2307/747800.

Ziegler, J. C., \& Goswami, U. (2005). Reading acquisition, developmental dyslexia, and skilled reading across languages: A psycholinguistic grain size theory. Psychological Bulletin, 131(1), 3-29. doi:10.1037/00332909.131.1.3. 